\title{
An Experimental Study of Rotor Fault Detection Using Motor Current Signature Analysis Based on Neural Networks
}

\author{
Rajul Misra $^{1}$ and G. L. Pahuja ${ }^{2}$ \\ ${ }^{1,2}$ EED, NIT Kurukshetra \\ Haryana-132119, India \\ ${ }^{1}$ rajulmisra71@gmail.com, 2pahuja.gl@gmail.com
}

\begin{abstract}
Now - adays in industrial practices continuous improvement of quality, productivity with lesser operating cost is desirable. To obtain these goals improvement in the maintenance practices and cost reduction are very important. As maintenance personnel, one has to know the reasons of failure, maintenance practices and the knowledge of the state of the art technologies. In most of real time industrial practices induction motors play a significant role and their reliable and safe operations is always desirable. In this paper a comprehensive idea of various faults, causes, detection parameter, techniques and latest trends in the condition monitoring technologies have been incorporated. To illustrate firstly a real time application of rotor fault by conventional Motor Current Signature Analysis (MCSA) based on measurement of sidebands in the stator current spectrum has been demonstrated. Thereafter an intelligent technique based on Neural Networks (NNs) has been proposed; tested and simulated that proclaims reliable and efficient operation.
\end{abstract}

Keywords: Motor Current Signature Analysis, Induction Machine, Fault Diagnosis, Neural Networks

\section{Introduction}

Induction motors play a very important role in the safe and efficient running of industrial plants and processes due to its low cost, robustness and economical maintenance. Early detection of faults in the motors will help avoid expensive failures. Condition monitoring of these machineries can significantly reduce the cost of maintenance and the risk of unexpected failures by allowing the early detection of potentially catastrophic faults. Due to the complex and nonlinear relation between the machine variables and fault phenomena and also the occurrence of multiple faults simultaneously, a rigorous analysis is required to interpret the data in relation with the occurred fault [10-12]. To address these issues intelligent techniques, such as NN, Fuzzy logic, Expert systems, Genetic Algorithm, hybrid systems and many more are other approaches have been reported by Singh et al., [18]. Filippetti, et al., [19] used NeuroFuzzy system for detecting existence and severity of inter-turn fault with motor currents and voltages as inputs. Zidani [21] proposed a fuzzy decision making system using Park vector extracted patterns to identify stator winding turn faults. But one has to learn background knowledge of the system. Tallam presented a negative-sequence equivalent circuit for detecting induction motor stator winding fault [20]. Intelligent systems are valuable as compared to conventional monitoring techniques due to non requirement of modeling equations of the faulty system and need a priori knowledge for implanting the monitoring tools and techniques. In addition to its intelligent systems are helpful in improving the automation of the monitoring process. In this paper an online monitoring based on NNs has been carried out for rotor fault detection of induction motor in Jindal Steel \& Power Limited, Raigarh, India. It needs to be stated that the 
proposed scheme doesn't require a priori knowledge of the system. The rest of the paper contains four sections structured as follows: Section 2 illustrated the faults indicators, testing, monitoring and detection techniques, in Section 3 experimental study have been shown, while simulation studies and results have been shown in Section 4. Finally conclusions have been drawn in last Section.

\section{Fault Indicator}

Faults in induction motors [1,3] have been categorized according to the main components of fault in stator, rotor, bearings and in others. To add various surveys of faults of large induction motors conducted by IEEE-IAS, EPRI [4-6] and Allianz [7] are exhibited in Table 1.

Table 1. Comparison of IEEE IAS, EPRI, ALLIANZ Surveys

\begin{tabular}{|l|l|l|l|}
\hline \multirow{2}{*}{$\begin{array}{l}\text { Major } \\
\text { components }\end{array}$} & \multicolumn{3}{|l|}{ Percentage of failures } \\
\cline { 2 - 4 } & $\begin{array}{l}\text { IEEE } \\
\text { IAS }\end{array}$ & EPRI & ALLIANZ \\
\hline $\begin{array}{l}\text { Bearing related } \\
(\%)\end{array}$ & 44 & 41 & 13 \\
\hline Rotor related (\%) & 08 & 09 & 13 \\
\hline Stator related (\%) & 26 & 36 & 66 \\
\hline Others fault (\%) & 22 & 14 & 08 \\
\hline
\end{tabular}

The induction motor is highly symmetrical and any presence of faults affects its symmetry. This yields a corresponding change in the interaction of flux between the stator and rotor, consequential changes to the stator currents, voltages, magnetic field and machine vibrations. Furthermore, these signals can be used for online condition monitoring. According to Nandi and Toliyat [2], the major faults arising in induction motor are classified as:

- Stator faults resulting in the opening or shorting of the winding,

- Turn to ground faults,

- Abnormal connection of the stator windings,

- Broken rotor bar or cracked rotor end-rings,

- Static and/or dynamic air-gap irregularities,

- Bent shaft which results in rub between the stator and rotor, causing serious damage to the stator core and windings,

- Shorted rotor field winding,

- Demagnetization of permanent magnets,

- Bearing and gearbox faults.

\subsection{Testing and Monitoring Methods}

The testing and monitoring methods can be mainly classified into online and offline testing. In offline mode the observed motor required to be removed from service, whereas in online monitoring mode the motor is kept in running operation. The various testing and monitoring methods are as follows:

\section{a. Visual Monitoring}

In this method motor is simply inspected by the unaided eye, through the use of borescopes for better observation, use of microscopes to increase magnification if needed, and CCTVs. 


\section{b. $\quad$ Vibration monitoring}

This is the oldest traditional monitoring technique and widely used to detect mechanical faults like mechanical imbalance and bearings failure. A piezo-electric transducer is used to sense the acceleration of a moving part and provided acceleration signal can be used to convert into velocity or position signal. Vibration monitoring systems can be categorized mainly into data acquisition, feature extraction and condition classification. Data are gathered using transducers.

\section{c. Current monitoring}

Some faults can be monitored and detected by measuring the voltages or currents in the windings. When faults occur, magnetic field generated which changes in flux. Hence search coils can also be used in condition monitoring. The stator current is commonly measured by using a Hall-effect transducer. It contains frequency components which can be correlated to a variety of faults.

\section{d. $\quad$ Voltage monitoring}

Stator voltage can be measured by using a high frequency differential voltage probe or isolation amplifier and it can be used to determine the instantaneous power, torque and negative sequence impedance.

\section{e. Flux monitoring}

Penman et al., [13] proposed a method to detect inter-turn faults by analyzing the axial flux component of machine using a large coil wound concentrically around the shaft of the machine. Even the fault position could be detected by mounting four coils symmetrically in four quadrants of the motor at a radius of about half the distance from the shaft to the stator end winding. This technique works properly in the case of presenting supply harmonics but it can't be used extensively in industry because of installing search coils. In addition to it proposed scheme is heavily dependant on the motor load torque which makes setting alarm levels very difficult.

\section{f. Air gap Torque}

The air gap torque is sensitive to unbalances created by any kind of fault e.g., unbalanced supply voltages, cracked rotor bars or asymmetric stator winding, which is generated by the flux linkage and the currents of a rotating machine. Hsu [14] studied air gap torque frequency components in detecting inter-turn short-circuit fault proclaiming the non-zero angular frequency of the torque displaying the faulty situation of the motor.

\section{g. Sequence Component}

Negative sequence current component of the motor's phase currents has been introduced as the first indicator for inter-turn fault diagnosing. Toliyat and Lipo [15] showed variation of this parameter in existence of stator winding asymmetries. Since, negative sequence current mainly depends on unbalance supply voltage, apparent negative-sequence impedance is further introduced as an inter-turn fault indicator by Sottile et. al., [16].

\section{h. Temperature Monitoring}

Inter-turn fault produces excessive heating which can harm the insulation. Tallam et. al., [17] reported the fact that for each $10^{\circ} \mathrm{C}$ increase in the temperature there is $50 \%$ loss of insulation life. So stator thermal inspection is very necessary in prolonging motor life and can be used as fault monitoring technique. 


\subsection{Fault Detection Techniques}

\section{a. Complex park vector}

When 3- $\Phi$ balanced supply system is given to healthy motor then park vector forms a circle centered in the origin of the $d-q$ plane with constant radius. In case of faulty condition motor mimics as an unbalanced load. Such unbalance causes an oscillation in the radius of park vector and turned into elliptical shapes as shown in Figure 1.
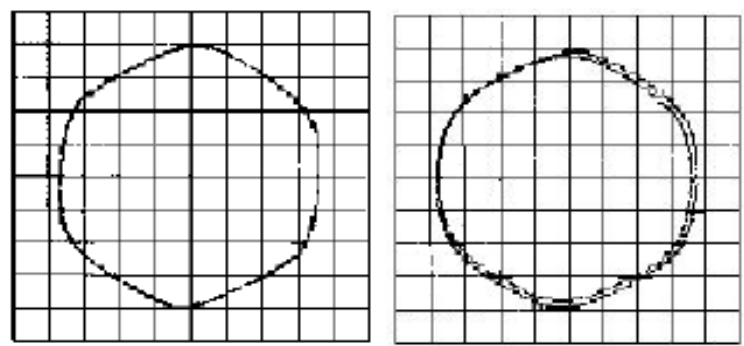

Figure 1. Park Vector for Healthy Motor (left) and Motor with Fault (right)

\section{b. MCSA method}

The most common method for both stators as well as for rotor fault detection is based on MCSA [23-29]. In this method the information given by stator current sensors are necessary to analyze the motor behavior. This approach uses the lower sideband (LSB) and upper sideband (USB) around the fundamental frequency $F_{L}$. When a rotor fault (asymmetry) occurs, the amplitude differences of current at $\mathrm{F}_{\mathrm{L}}$ to USB and LSB changes. This occurrence may be accounted for as the result of a backward rotating field induced by the rotor fault [30]. LSB and USB are not the only effected due to the rotor broken bars but some other frequencies are also induced in the stator current which go insufficiently to explained and that can give more information about the rotor asymmetry and the fault severity. Various researches related to analytical approach of the stator current frequency components for the detection of electrical faults have been reported [31-34].An ideal current spectrum for healthy motor is shown in the Figure 2, which shows LSB and USB due to broken rotor bars around the $\mathrm{F}_{\mathrm{L}}$.

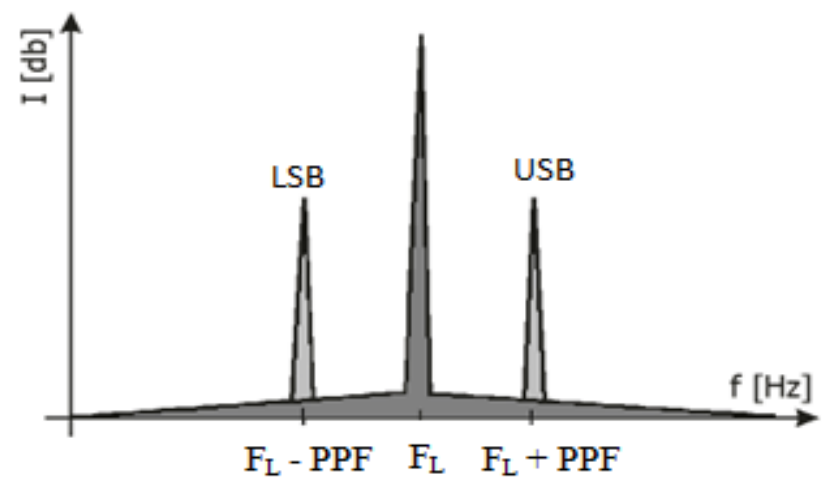

Figure 2. Ideal Current Spectrums

A decibel $(\mathrm{dB})$ versus frequency spectrum is used to give wide dynamic range and detect the unique current signature patterns that are the characteristics of different faults. On the basis of current patterns the condition of the rotor is identified. A rotor fault in motor mainly depends upon slip frequency and pole pass frequency (PPF). The slip 
frequency is the difference between normal speed and actual speed. Generally in motor the numbers of poles are known and PPF can be determined. The peaks of sidebands can be determined by the Equation 1

$$
\mathrm{F}_{\mathrm{L}} \pm \mathrm{PPF}
$$

On the basis of current patterns the condition of the rotor is identified as tabulated in Table 2 [8-9].

Table 2. Condition of the Rotor

\begin{tabular}{|l|l|}
\hline $\begin{array}{l}\text { Amplitude } \\
\text { difference }(\mathrm{dB})\end{array}$ & $\begin{array}{l}\text { Rotor condition } \\
\text { (with at least 75\% of rated load ) }\end{array}$ \\
\hline$>60$ & Excellent \\
\hline $54-60$ & Good \\
\hline $48-54$ & Moderate \\
\hline $42-48$ & $\begin{array}{l}\text { Bar crack may be developing or high resistance } \\
\text { joints }\end{array}$ \\
\hline $36-42$ & $\begin{array}{l}\text { Two bars may be cracked or high resistance } \\
\text { joints likely }\end{array}$ \\
\hline $30-36$ & $\begin{array}{l}\text { Multiple cracked or open bars or end ring } \\
\text { probable }\end{array}$ \\
\hline$<30$ & $\begin{array}{l}\text { Multiple broken bars and/or end rings very } \\
\text { likely }\end{array}$ \\
\hline
\end{tabular}

\section{Experimental Study}

Roughly more than hundred experimental studies aimed to find out fault detection of induction motor have been carried out in Jindal Steel \& Power Limited, Raigarh, India and few of them are tabulated in Table 3.

Table 3. Important Parameters of Motors

\begin{tabular}{|l|l|l|l|l|l|l|l|l|l|l|}
\hline SN. & $\begin{array}{l}\text { Power } \\
\text { output } \\
(\mathrm{KW})\end{array}$ & $\begin{array}{l}\text { Current } \\
(\mathrm{A})\end{array}$ & $\begin{array}{l}\text { Rotor } \\
\text { bars }\end{array}$ & $\begin{array}{l}\text { Stator } \\
\text { slots }\end{array}$ & $\begin{array}{l}\text { Running } \\
\text { speed } \\
(\mathrm{Hz})\end{array}$ & $\begin{array}{l}\text { PPF } \\
(\mathrm{Hz})\end{array}$ & $\begin{array}{l}\text { Load } \\
(\%)\end{array}$ & $\begin{array}{l}\text { USB } \\
(\mathrm{dB})\end{array}$ & $\begin{array}{l}\text { LSB } \\
(\mathrm{dB})\end{array}$ & Index \\
\hline 1 & 480.0 & 54.00 & 88 & 72 & 12.288 & 0.940 & 84.1 & -81.3 & -76.3 & 0.0845 \\
\hline 2 & 365.0 & 40.00 & 58 & 48 & 24.713 & 0.482 & 32.2 & -61.7 & -58.2 & 0.5056 \\
\hline 3 & 350.0 & 36.5 & 50 & 60 & 24.340 & 0.436 & 77.5 & -37.7 & -39.7 & 5.0883 \\
\hline 4 & 661.0 & 72 & 58 & 72 & 16.231 & 0.550 & 68 & -43.1 & -44.1 & 2.6594 \\
\hline 5 & 570.0 & 61 & 58 & 48 & 24.598 & 0.573 & 78.5 & -55.5 & -57.9 & 0.6752 \\
\hline
\end{tabular}

The current signature patterns for all cases have been shown in Figure 3 to Figure 7. 


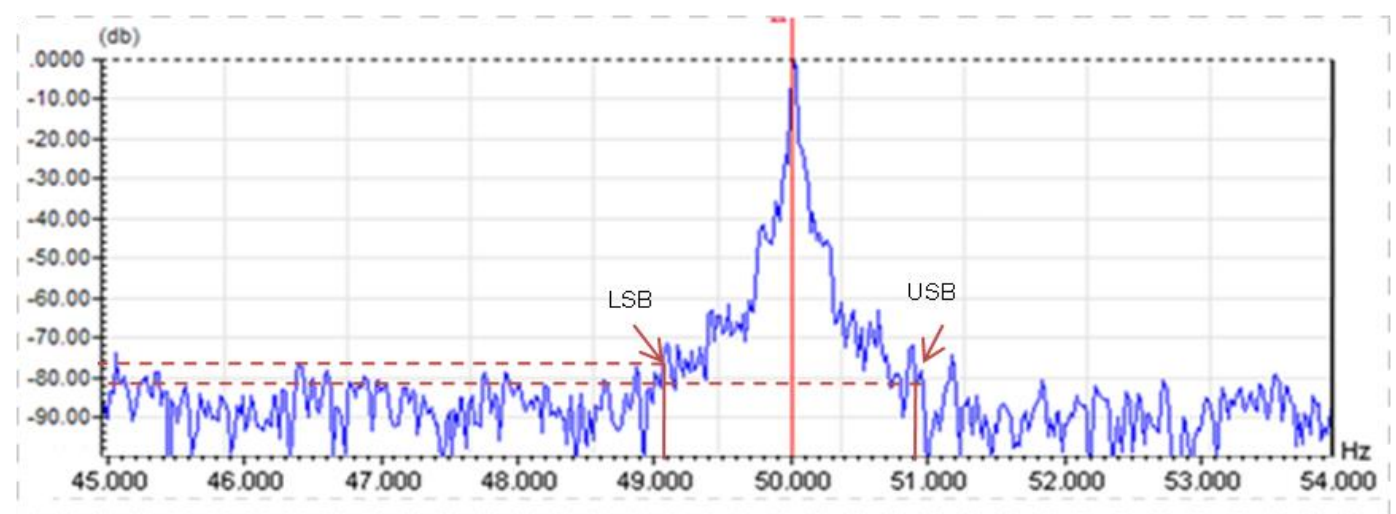

Figure 3. Current Signature Patterns for Case 1

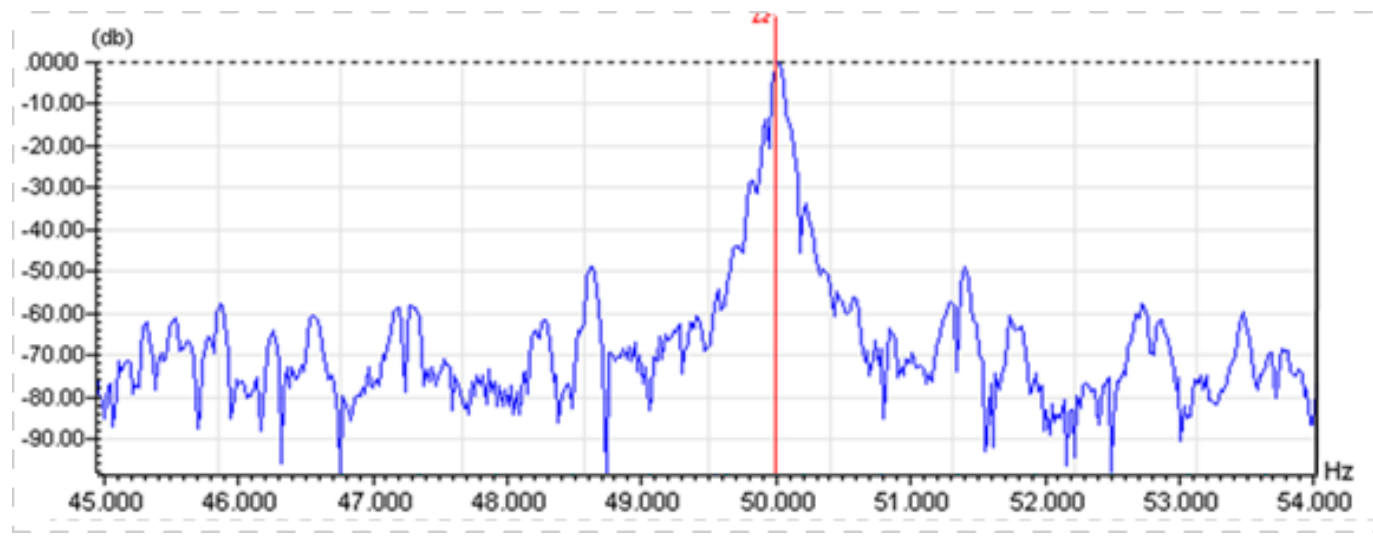

Figure 4. Current Signature Patterns for Case 2

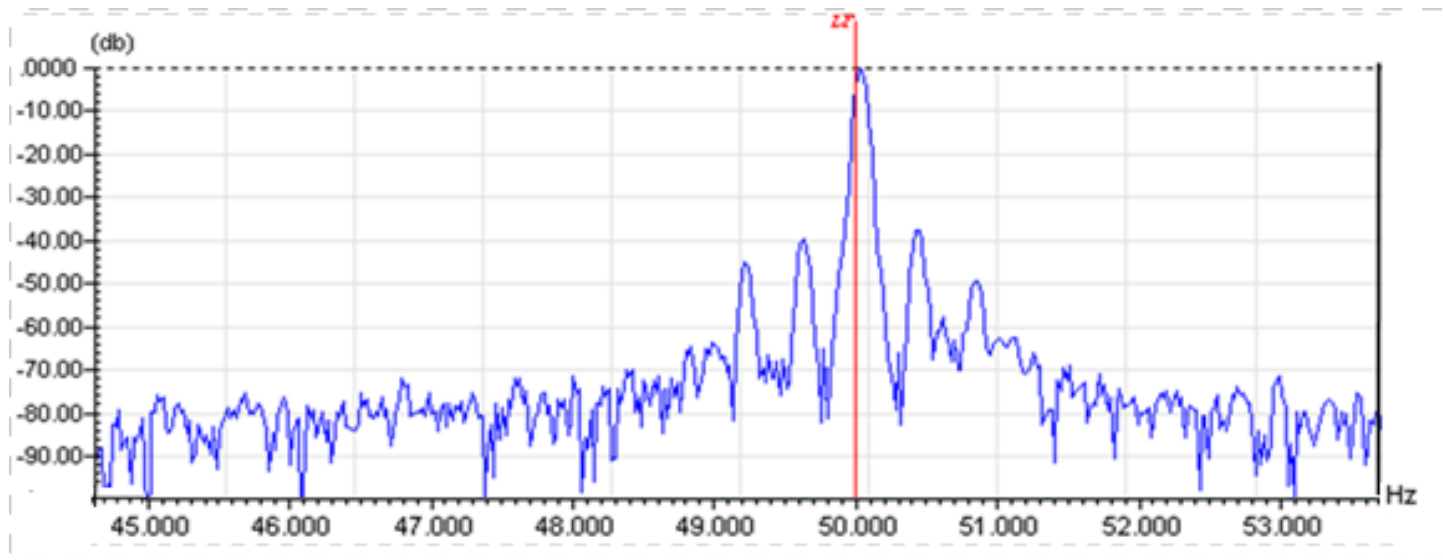

Figure 5. Current Signature Patterns for Case 3 


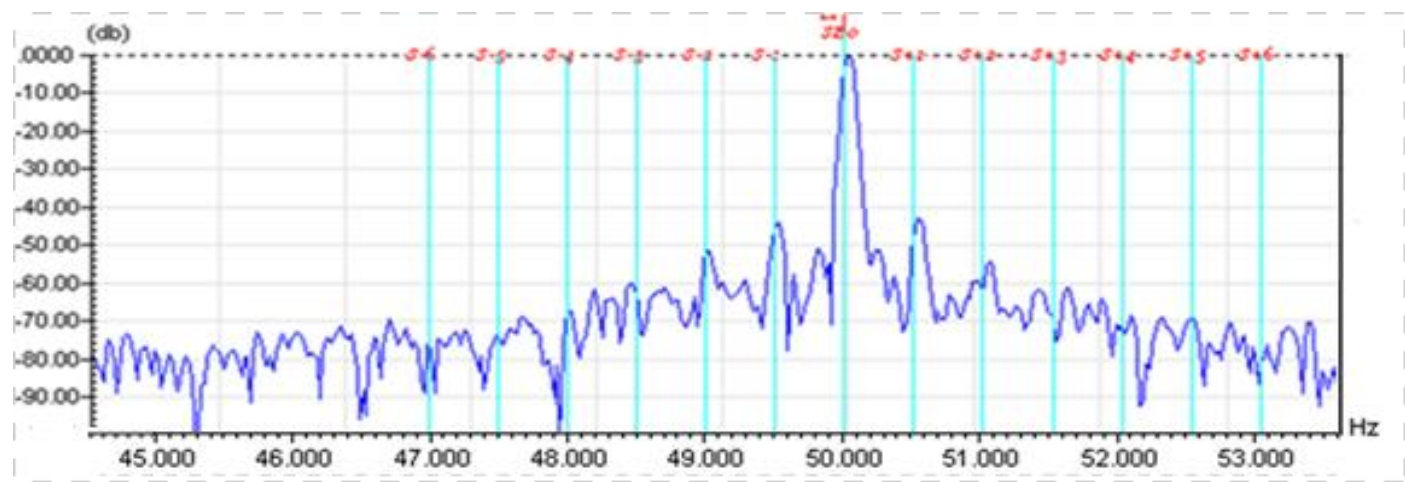

Figure 6 Current Signature Patterns for Case 4

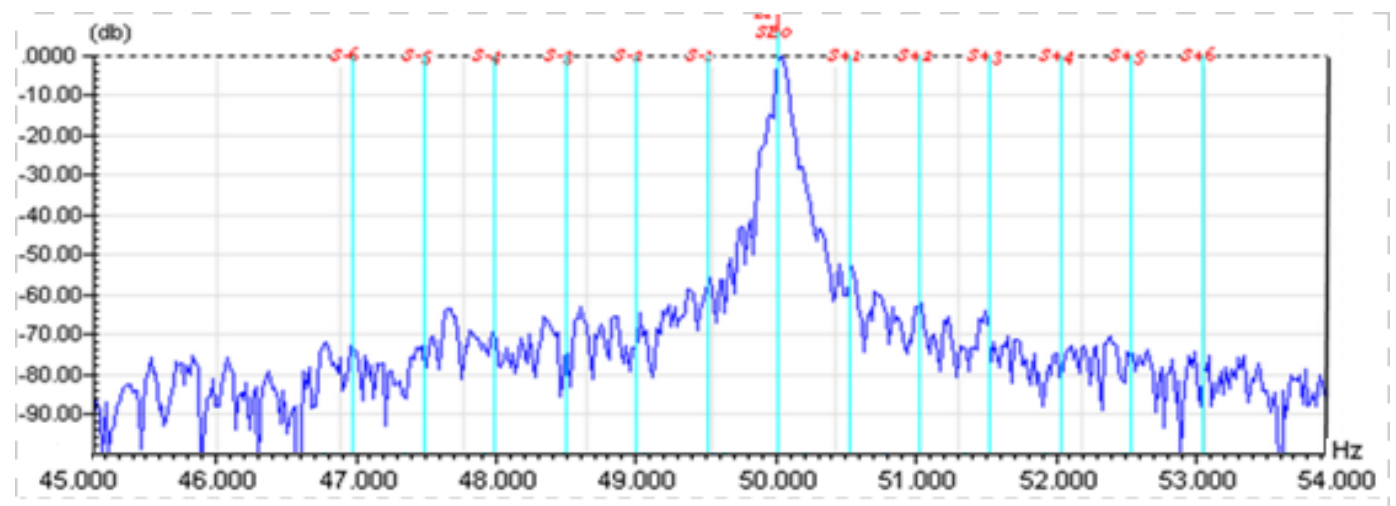

Figure 7. Current Signature Patterns for Case 5

In all these case studies supply voltage of 6600 volts has been considered. Rotor faults in motor mainly depend upon slip frequency and pole pass frequency (PPF). The slip frequency is the difference between normal speed and actual speed. Generally in motor the numbers of poles are known and by multiplying number of poles to the frequency, PPF can be determined. A fault in rotor circuit creates upper sideband (USB) and lower sideband (LSB) around the shaft rate harmonics. In case 1 as shown Figure 3 the value of PPF is $0.940 \mathrm{~Hz}$ and motor is $84.1 \%$ loaded and peaks are clearly observed. The values of USB and LSB are $-81.3 \mathrm{~dB}$ and $-76.3 \mathrm{~dB}$ respectively. The differences in amplitude between the line frequency peak to USB and LSB is an indication of the rotor bar health. For healthy motor amplitude difference should be high. The difference of greater than 60 $\mathrm{dB}$ indicates an excellent rotor bar condition. Under faulty condition of the motor (i.e., high resistance joints or cracks in rotor bar), the rotor impedance rises. Due to this, the current drawn at the PPF frequency increases, misleading to an increase in the amplitude of the PPF peaks in the current spectrum. A difference of about $48 \mathrm{~dB}$ would indicate the presence of high resistance joints whereas difference of about $35 \mathrm{~dB}$ indicates multiple broken bars. An estimation of number of broken bars (broken bar factor) can be obtained from the Eq.2. [22].

$$
n=\frac{2 R}{\left(\frac{N}{10^{20}+p}\right)}=\frac{2 \times 58}{\left(\frac{43.6}{10^{20}+2}\right)}=0.7430718
$$

Where $n$ is the index (estimate of number of broken bars), $\mathrm{R}$ is number of rotor slots, $\mathrm{N}$ represents average $\mathrm{dB}$ difference between USB and LSB and supply component= $(43.1+44.1) / 2=43.6 \mathrm{~dB}$ and $p$ is the pole pairs which is 2 . The index is 0.7430718 but Eq. 
2 is applied for full load operation and this has to be modified since the MCSA measurement performed on reduced load. After applying the correction factor for this load and particular motor design (commercially sensitive and cannot be shared) finally index has been determined 2.6594. Table 4 depicts the rotor health on the basis of index.

Table 4. Rotor Health on the Basis of Index

\begin{tabular}{|c|l|l|l|l|}
\hline SN. & USB & LSB & Index & Rotor health \\
\hline 1. & -75.3 & -78.3 & 0.0845 & Excellent \\
\hline 2. & -61.7 & -58.2 & 0.5056 & $\begin{array}{l}\text { Rotor bar crack may be developing or } \\
\text { problems with high resistance joint }\end{array}$ \\
\hline 3. & -37.7 & -39.7 & 5.0883 & $\begin{array}{l}\text { Multiple broken rotor bars and end rings } \\
\text { very likely. Severe problems throughout }\end{array}$ \\
\hline 4. & -43.3 & -44.1 & 2.6594 & $\begin{array}{l}\text { Multiple cracked or broken rotor bars } \\
\text { and end rings indicated. Also joint and } \\
\text { ring problems }\end{array}$ \\
\hline 5. & -55.5 & -57.9 & 0.6752 & $\begin{array}{l}\text { Rotor bar crack may be developing or } \\
\text { problems with high resistance joint }\end{array}$ \\
\hline
\end{tabular}

The range of index and rotor health has been considered and shown in Table 5.

Table 5. Rules for Rotor Health

\begin{tabular}{|c|l|l|}
\hline Sr. No. & Range of Index & Rotor health \\
\hline 1. & 0.00 to 0.10 & Excellent \\
\hline 2. & 0.10 to 0.25 & Good \\
\hline 3. & 0.25 to 0.39 & Alert \\
\hline 4. & 0.39 to 0.90 & Damaged \\
\hline 5. & 0.90 and above & Seriously damaged \\
\hline
\end{tabular}

\section{Simulation, Results and Discussions}

To test the effectiveness of proposed scheme all simulation has been carried out on MATLAB R2010a. It is well observed from Eq.2 that there is very strong nonlinear relationship between index and USB and LSB. Since NNs are universal approximations and also have inherent capabilities to deal with nonlinearity [35] therefore NNs have been considered as a perfect tool for the proposed scheme. An experiment has been performed to determined number of hidden layers and number of hidden neurons for each layer. Two (02) hidden layers, five (05) and eight (08) hidden neurons have been found as optimum choice. Tan Sigmodial activation function has been chosen for hidden layer and linear activation function has been chosen for output layer. The simulation parameters are chosen as follows:

Table 6. Simulation Parameter

\begin{tabular}{|r|l|l|}
\hline S.No & Parameter & Value \\
\hline 1. & Learning rate & 0.02 \\
\hline 2. & Momentum coefficient & 0.9 \\
\hline 3. & Performance goal & 0.001 \\
\hline 4. & Maximum epochs & 3000 \\
\hline 5. & Training algorithm & $\begin{array}{l}\text { Levenberg- } \\
\text { Marquardt }\end{array}$ \\
\hline
\end{tabular}


The configuration of $\mathrm{NN}$ has been shown in Figure 8.

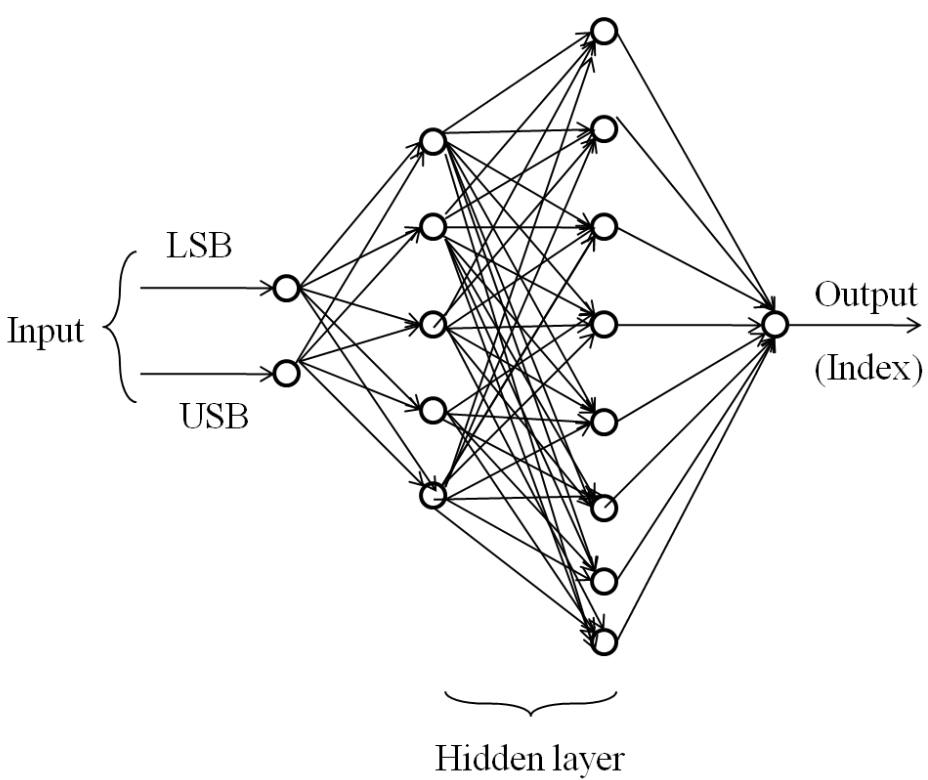

Figure 8. Configuration of NN

The inputs for NN are LSB and USB and output of network is Index. Data relating to one hundred (100) faults i.e., Current patterns along with USB and LSB have been collected and digitized. $80 \%$ data have been used for training and rest unseen cases have been utilized for testing. The convergence of training is shown in Figure 9 and NN meets the performance goal in 1541 epochs. The errors have been plotted and shown in Figure 10 and it is observed that minimum $96.5 \%$ accuracy has been obtained.

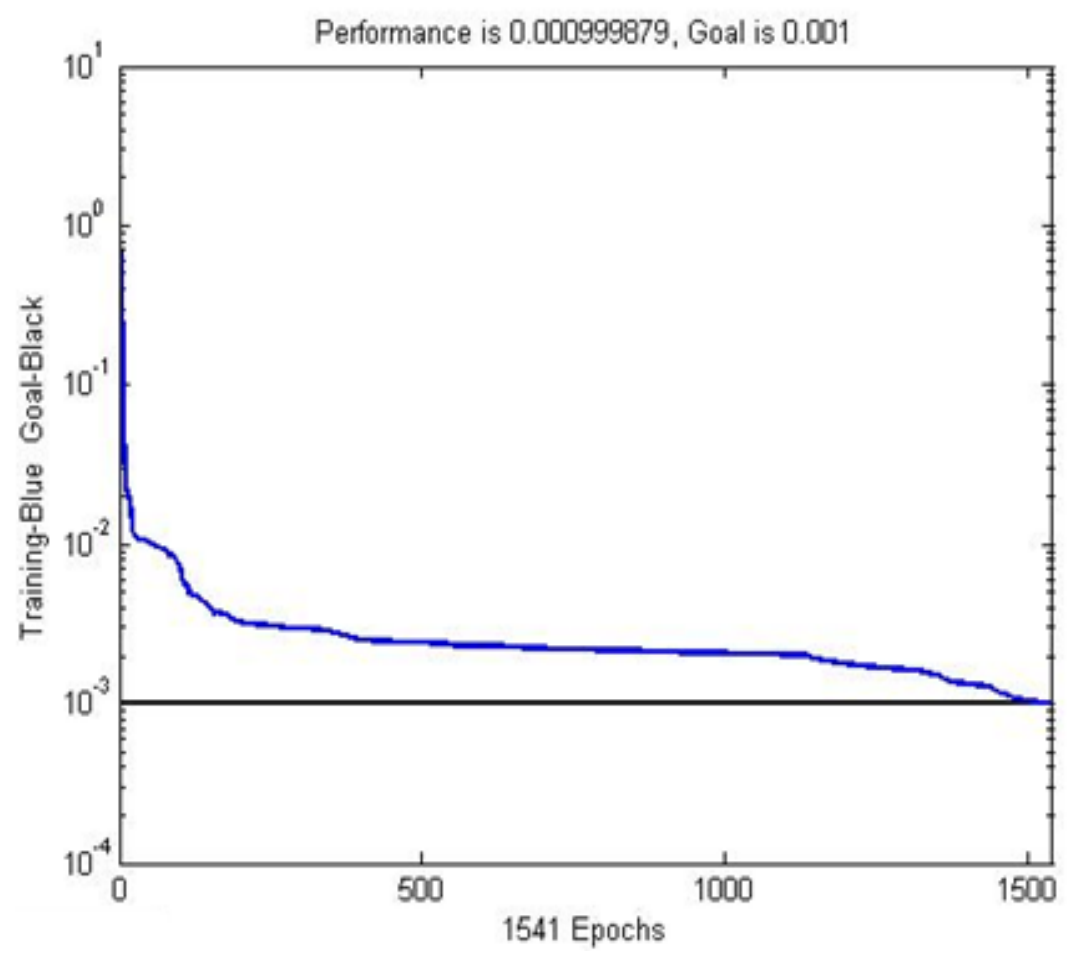

Figure 9. Convergence of Training 


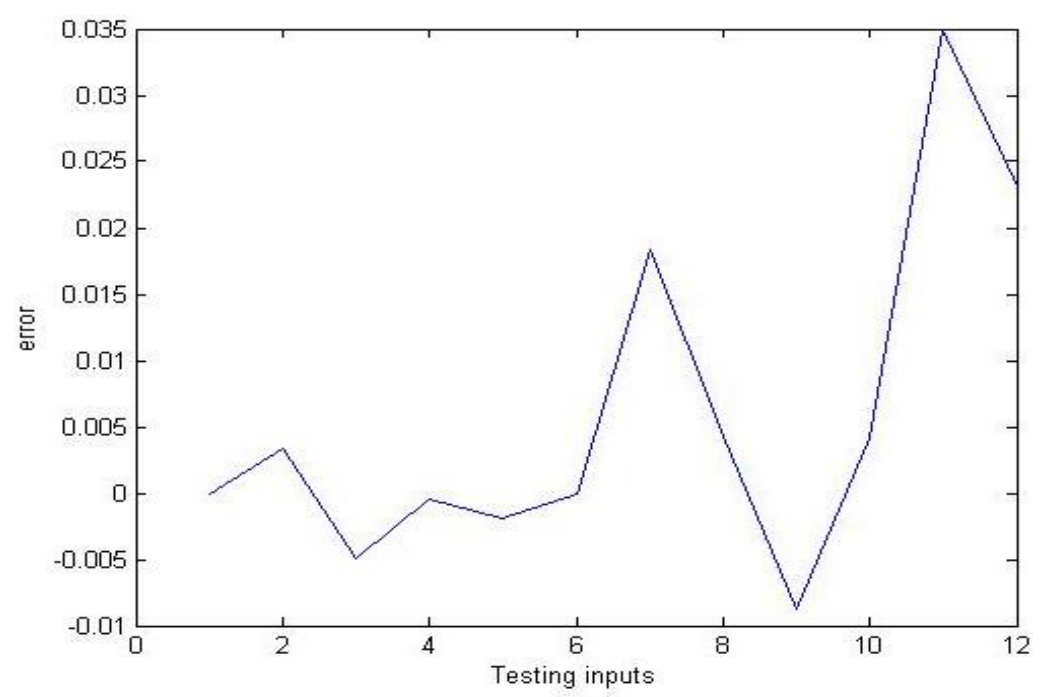

Figure 10. Error

The results of 12 cases are reported as follows:

Table 7. Results

\begin{tabular}{|c|l|l|}
\hline S.N & Index & Rotor Health \\
\hline 1. & 0.907192 & Seriously damaged \\
\hline 2. & 0.299895 & Alert \\
\hline 3. & 1.170987 & Seriously damaged \\
\hline 4. & 2.441899 & Seriously damaged \\
\hline 5. & 0.513113 & Damaged \\
\hline 6. & 1.307174 & Seriously damaged \\
\hline 7. & 1.064989 & Seriously damaged \\
\hline 8. & 0.609815 & Damaged \\
\hline 9. & 0.177121 & Good \\
\hline 10. & 0.062442 & Excellent \\
\hline 11. & 0.0896 & Good \\
\hline 12. & 0.3177 & Alert \\
\hline
\end{tabular}

All these results have been tested and verified from Jindal Steel \& Power Limited, Raigarh, India.

\section{Conclusions}

Condition monitoring can improve the reliability and reduce the maintenance costs of motors. A brief illustration of Fault indicators, testing and monitoring methods and fault detection techniques has been presented. Due to ability to detect online rotor fault detection by MCSA has been used. The data for 100 cases have been collected and NN has been used to identify the rotor faults. On the basis of simulation results it is concluded that the proposed scheme is able to detect online rotor health of the motor.

\section{Acknowledgements}

Rajul Misra acknowledges valuable facilities provided by the Moradabad Institute of Technology, Moradabad in preparation of the research. He also acknowledges Jindal Steel \& Power Limited, Raigarh, India for sharing experimental data. 


\section{References}

[1] S. Williamson and P. Mirzoian, "Analysis of cage induction motor with stator winding faults", EEEPES, Summer Meeing, (1984).

[2] S. Nandi, H. A. Toliyat and L. Xiadong, "Condition Monitoring and Fault Diagnosis of Electrical machines -A Review", IEEE Transactions on Energy Conversion, vol. 20, no. 4, (2005) December, pp. 719-729.

[3] R. R. Schoen, T. G. Habetler, F. Kamran and R. G. Bartheld, "Motor bearing damage detection using stator current monitoring", IEEE Trans. Ind. Applns., vol. 31, no. 6, (1995) November-December, pp 1274-79.

[4] P. O. Donnell, "Report of large motor reliability survey of industrial and commercial installations", Part II, IEEE Trans. Ind. Appl., vol. IA-21, no. 4, (1985) July-August, pp. 865-872.

[5] P. O. Donnell, "Report of large motor reliability survey of industrial and commercial installations: Part 3", IEEE Trans. Ind. Appl., vol. IA-23, no. 1, (1987) January-February, pp. 153-158.

[6] P. F. Albrecht, J. C. Appiarius, R. M. McCoy, E. L. Owen and D. K. Sharma, "Assessment of the reliability of motors in utility applications-Updated", IEEE Trans. Energy Convers., vol. EC-1, no. 1, (1986) March, pp. 39-46.

[7] H. O. Seinsch, "Monitoring und Diagnose elektrischer Maschinen und Antriebe", Proc. VDE Workshop, Allianz Schadensstatistik an HS Motoren, (2001).

[8] E. Styvaktakis, M. H. J. Bollen and I. Y. H. Gu, "Expert System for Classification and Analysis of Power System Events", IEEE Trans. on Power Delivery, vol. 17, no. 2, (2002) April, pp. 423- 428.

[9] F. Filippetti and M. Martelli, "Development of Expert System Knowledge Base to On-Line Diagnosis of Rotor Electrical Faults of Induction Motors", IEEE Ind. Appl. Society Annual Meeting, vol. 1, (1992), pp. 92-99.

[10] A. F. Atiya and A. G. Palos, "Newresults on recurrent network training: Unifying the algorithms and accelerating convergence", IEEE Trans. Neural Network, vol. 13, (2000) May, pp. 765-786.

[11] X. Z. Gao and S. J. Ovaska, "Motor fault detection using Elman neural network with genetic algorithmaided training”, Proc. IEEE Int. Conf. Syst., Man, Cybern., vol. 4, (2000), pp. 2386-2392.

[12] M. Norgaard, O. Ravn, N. K. Poulsen and L. K. Hansen, "Neural Networks for Modeling and Control of Dynamic Systems", Berlin, Germany: Springer-Verlag, (2000).

[13] P. Tavner and J. Penman, "Condition Monitoring of Electrical Machines", Research Studies Ltd., London, England, (1987).

[14] J. S. Hsu, "Monitoring of defects in induction motors through air-gap torque observation", IEEE Trans. on Industry Applications, vol. 31, no. 5, (1995), pp. 1016-1021.

[15] H. A. Toliyat and T. A. Lipo, "Transient analysis of cage induction machines under stator, rotor bar and end ring faults", IEEE Trans. on Energy Conversion, vol. 10, no. 2, (1995) June, pp. 241247.

[16] J. Sottile, F. C. Trutt and J. L. Kohler, "Condition monitoring of stator windings in induction motors", II. Experimental investigation of voltage mismatch detectors, IEEE Trans. on Industry Applications, vol. 38, no. 5, (2002), pp. 1454-1459.

[17] M. R. Tallam, S. B. Lee, G. C. Stone, G. B. Kliman, J. Yoo, T. G. Habetler and R. G. Harley, "A survey of methods for detection of stator-related faults in induction machines", IEEE Trans. on Industry Applications, vol. 43, no. 4, (2007), pp. 920-932.

[18] G. K. Singh and S. A. S. Al Kazzaz, "Induction machine drive condition monitoring and diagnosis research- a survey", Journal of Electric Power System Research, vol. 64, no. 2, (2003), pp. 145-158.

[19] F. Filippetti, G. Franceschini, C. Tassoni and P. Vas, "Recent developments of induction motor drives fault diagnosis using AI techniques IEEE Trans. Industrial Electronics, vol. 47, no. 5, (2000) October, pp. 994-1004.

[20] R. M. Tallam, T. G. Habetler and R. G. Harley, "Experimental testing of a neural-network-based turnfault detection scheme for induction machines under accelerated insulation failure conditions", Proc. 4th Int. Symposium Diagnostics for Electric Machines, Power Electronics and Drives, (2003), pp. 58-62.

[21] F. Zidani, M. E. H. Benbouzid, D. Diallo M. S. Nait-Said, "Induction motor stator faults diagnosis by a current Concordia pattern-based fuzzy decision system", IEEE Trans. on Energy Conversion, vol. 18, no. 4, (2003), pp. 469-475.

[22] W. T. Thomson and D. Rankin, "Case histories of rotor winding fault diagnosis of induction motor", Proceedings $2^{\text {nd }}$ International conference on condition monitoring, university college of Swansea, Wales, United Kingdom, (1987).

[23] H. Henao, C. Martis and G. A. Capolino, "An equivalent internal circuit of the induction machine for advanced spectral analysis", Conf. Rec. IEEE-IAS Annu. Meeting, Pittsburgh, PA, vol. 2, (2002) October, pp. 739-745.

[24] H. Henao, C. Martis, G. Capolino and M. Radulescu, "Harmonic characteristics of an induction machine connected to a distribution network", Proc. IEEE IECON'02, Seville, Spain, vol. 2, (2002) November, pp. 1008-1013.

[25] H. Henao and G. A. Capolino, "A circuit-oriented model of induction machine for diagnosis", Proc. SDEMPED’97, Carry-le-Rouet, France, (1997) September, pp. 277-282. 
[26] J. Milimonfared, H. M. Kelk and S. Nandi, "A novel approach for broken rotor bar detection in cage induction motors", IEEE Trans. Ind. Appl., vol. 35, no. 5, (1999) September-October, pp. 1000-1006.

[27] G. B. Kliman and R. A. Koegl, "Noninvasive detection of broken rotor bars in operating induction motors", IEEE Trans. Energy Convers., vol. 3, no. 4, (1988) December, pp. 873-879.

[28] S. Nandi and H. A. Toliyat, "Condition monitoring and fault diagnosis of electrical machines-A review", Conf. Rec. IEEE-IAS Annu. Meeting, vol. 1, (1999), pp. 197-204.

[29] W. T. Thomson and M. Fenger, "Current signature analysis to detect induction motor faults", IEEE Ind. Appl. Mag., vol. 7, no. 4, (2001) July-August, pp. 26-34.

[30] A. Bellini, F. Filippetti, G. Franceschini, C. Tassoni and G. B. Kliman, "Quantitative evaluation of induction motor broken bars by means of electrical signature analysis", IEEE Trans. Ind. Appl., (2001) September-October, vol. 37, no. 5, (2001), pp. 1248-1255.

[31] G. Didier, H. Razik and A. Rezzoug, "On the modeling of induction motor including the first space harmonics for diagnostic purposes", Proc. ICEM'02, Brugges, Belgium, (2002) August.

[32] H. Razik, A. Abed, G. Didier, F. Weinachter and A. Rezzoug, "Analysis of the current spectral of an induction motor for diagnostic purposes”, Proc. ICEM'02, Brugges, Belgium, (2002) August.

[33] H. Henao, C. Demian and G. A. Capolino, "A frequency-domain detection of stator winding faults in induction machines using an external flux sensor", Conf. Rec. IEEE-IAS Annu. Meeting, Pittsburgh, PA, vol. 3, (2002), pp. 1511-1516.

[34] H. Henao and G. A. Capolino, "Correlation between line current and axial leakage flux in induction machines", Proc. ICEM'02, Brugges, Belgium, (2002) August.

[35] S. Haykin, "Neural Networks", NJ: Prentice-Hall, A Comprehensive Foundation. Englewood Cliffs, (1999).

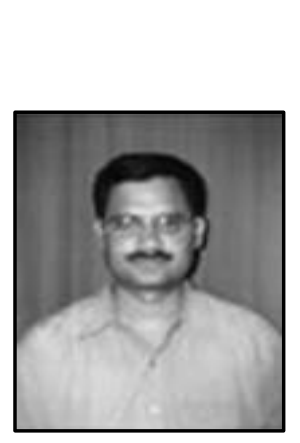

\section{Authors}

Rajul Misra was born in 1971 in India and received B.E. degree in Electrical Engineering from National Institute of Technology, Kurukshetra, India in 1996, and M.Tech. Degree in Electrical Engineering from the Motilal Nehru National Institute of Technology, Allahabad, India in 2005. He is currently, Associate Professor in EED, Moradabad Institute of Technology, Moradabad, India and pursuing research at NIT, Kurukshetra. His research interests include condition monitoring, diagnosis, protection of electric machines, design and control of motor drives.

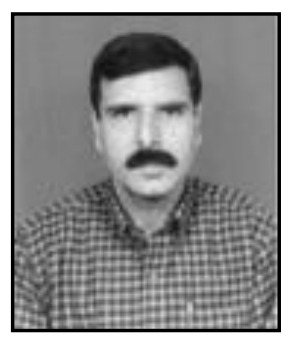

Dr G L Pahuja, is working as professor in Electrical Engineering Department, NIT Kurukshetra and completed B.Sc. (Electrical Engineering), M Tech (Control System), and PhD from REC Kurukshetra (Kkurukshetra University, Kuruksheta) in the area of Reliability Engineering. His research area includes System and Reliability Engg, Fault tolerant systems, Reliability evaluation and optimization of Computer and Computer Communication Networks, Reliability Centered Maintenance, multistage Interconnection networks etc. 